\title{
TEORIA CRÍTICA E OS SENTIDOS DA EMANCIPAÇÃO'
}

\author{
Rúrion Melo*
}

\begin{abstract}
A tradição de pensamento conhecida como Teoria Crítica, que conta com os nomes de Horkheimer, Adorno, Marcuse e Habermas, entre muitos outros, é composta por diferentes modelos críticos. Encontramos, numa mesma geração ou ainda num mesmo autor, diferentes formulações da crítica social apoiadas em diagnósticos do tempo renovados. O presente artigo procura pensar as condições de renovação dos diagnósticos a partir da qual os obstáculos à emancipação ou potenciais emancipatórios, quando presentes numa dada sociedade, sejam considerados e analisados de modo crítico. Essa renovação implica desvincular a fundamentação normativa da crítica do "paradigma produtivista" e conceber as lutas emancipatórias na pluralidade de seus sentidos.
\end{abstract}

PalAVRAS-CHAVE: teoria crítica, emancipação, novos movimentos sociais, democracia.

O que distingue uma teoria crítica das demais posturas teóricas no campo das ciências humanas consiste em seu interesse pelas condições emancipatórias socialmente existentes. Porém, além desse princípio geral, a teoria crítica se coloca uma forte exigência de fundamentar, de um ponto de vista imanente ao próprio objeto social, suas análises e diagnósticos sobre as condições de possibilidade e sobre os obstáculos existentes à emancipação. Uma vez que tais condições e obstáculos precisam estar presentes de algum modo na própria sociedade, transformações políticas, econômicas e culturais necessariamente influenciam todo diagnóstico crítico voltado para o problema da orientação emancipatória. O capitalismo liberal e a luta de classes, o capitalismo tar-

\footnotetext{
* Doutor em Filosofia. Professor da Universidade Federal de São Paulo (UNIFESP)/Campus Guarulhos. Estrada do Caminho Velho, 333. Pimentas. Cep: 07252312. Guarulhos - São Paulo. rurion.melo@unifesp.br

${ }^{1}$ Uma versão preliminar do presente texto foi apresentada no Seminário de Ciência Política da USP em junho de 2010. Agradeço a todos os participantes pelas críticas e sugestões. As ideias aqui reunidas resumem parte de minha tese de doutorado Sentidos da emancipação: para além da antinomia revolução versus reforma, defendida em 2009 no Departamento de Filosofia da USP.
}

dio e os direitos sociais de bem-estar, o reconhecimento de minorias culturais etc. compreendem fenômenos históricos diversos de formas de luta nas sociedades complexas e plurais. O desafio da teoria crítica consiste em poder renovar seus diagnósticos de modo a tornar possível que continuemos formulando uma perspectiva a partir da qual os obstáculos à emancipação ou potenciais emancipatórios, quando presentes numa dada sociedade, sejam considerados e analisados de modo crítico. Quais são as categorias e diagnósticos mais adequados hoje para levar adiante essa tradição de pensamento? Essa adequação não implica atrelar necessariamente nossas inspirações teóricas e intuições normativas a um novo diagnóstico sobre o Estado democrático de direito vinculado ao Ocidente capitalista?

Apesar de sua composição necessariamente heterogênea, a história dessa rica tradição de pensamento pode ser reconstruída a partir dos problemas teóricos e práticos surgidos inicialmente na teoria crítica de Marx, especialmente no que diz respeito à exigência teórica de fundamentar adequadamente a crítica social de modo imanente. 
Por essa razão, inicio apresentando o que entendo ser, desde sua fundação com Marx, a tarefa comum da teoria crítica na formulação de diagnósticos de época para a práxis emancipatória, ou seja, para a relação entre teoria e prática. Procuro frisar que se inicia, na década de 1930, uma primeira renovação da teoria crítica na versão de um "materialismo interdisciplinar", que foi seguida, em seu desdobramento específico, a partir da década seguinte, por um novo diagnóstico caracterizado pela desconfiança diante dos potenciais emancipatórios presentes no capitalismo tardio. Considerando que a orientação emancipatória ligada mais estreitamente ao projeto de Marx configurou suas abordagens teóricas e ideais práticos a partir do conceito de trabalho, faço, em seguida, um breve excurso apenas com o intuito de sublinhar que os limites da emancipação pelo trabalho, cristalizados nos clássicos paradigmas revolucionário e reformista, também engessaram a atividade política na utopia da sociedade do trabalho vinculada a um reducionismo funcionalista criado pelo paradigma produtivista. Foi preciso enfrentar o déficit normativo da primeira geração da teoria crítica e também fazer uma crítica ao próprio modelo de ação baseado no trabalho como orientação emancipatória predominante no projeto crítico como tal para dar continuidade a uma teoria crítica da sociedade. Do interior do debate entre diferentes abordagens críticas para se fundar adequadamente uma teoria atual da emancipação, o presente artigo procurará expor uma crítica ao paradigma produtivista e sublinhar a necessidade de uma reconstrução do conceito de emancipação não mais fundado no modelo de ação baseado no trabalho. O passo dos teóricos críticos que procuraram continuar os diagnósticos de época consiste em incluir, em suas respectivas renovações teóricas, categorias que permitissem explicar as novas formas de luta política e de mobilização cultural que ampliaram os sentidos da emancipação e configuraram atualmente o grande desafio das democracias. Isso se tornou possível, como mostrarei em minha última seção, quando abandonaram as orientações emancipatórias presas ao paradigma produtivista e estabeleceram uma reflexão sobre a gênese dos conflitos existentes a partir da compreensão das condições presentes da política e do direito.

\section{MARX E A TEORIA CRÍTICA}

A filiação autodeclarada da tradição de pensamento da teoria crítica a Marx e ao marxismo nem sempre se deixa ver de forma muito clara. O livro Dialética do esclarecimento, por exemplo, escrito conjuntamente por Max Horkheimer e Theodor Adorno e publicado em 1944 (Adorno; Horkheimer, 1985), é um forte sintoma de que muita coisa havia mudado nessa filiação, se tivermos como referência as formulações contidas em História e consciência de classe de Georg Lukács (2003). Desde a fundação da teoria crítica em 1929, em que se tratava de abrir novas possibilidades para o projeto hegeliano de esquerda, temas clássicos do marxismo foram reavaliados em função de conjunturas políticas e diagnósticos sociais sensivelmente modificados. Isso não significou, no entanto, que até mesmo o "abandono" das pretensões emancipatórias diagnosticado por Adorno e Horkheimer no Prefácio daquele livro de 1944 não estivesse ancorado, em alguma medida, numa atitude teórica crítica semelhante àquela adotada por Marx. Foi justamente esse vínculo com Marx que permitiu que a postura teórica de certa tradição de pensamento fosse qualificada como crítica, ainda que isso implicasse apontar para uma direção contrária àquela para a qual as próprias teses de seu suposto fundador nos levariam.

Em que sentido a teoria de Marx pode ser chamada de crítica? Não no mesmo sentido em que as teorias de autores como Lassale, Proudhon e Bakunin eram críticas em relação ao capitalismo e apontavam diferentes saídas para o futuro. ${ }^{2}$

A bibliografia sobre a crítica de Marx às outras formas de socialismo é extensa. Cf. especialmente Lichtheim (1965, 1969) e Draper (1990). 
O ímpeto transformador da práxis revolucionária, tantas vezes defendido por Marx, precisava ser fundamentado numa relação bem sucedida entre a teoria e a prática. Pois a práxis política não poderia mais se confundir com a "mera ação" nem com o simples desejo de mudança, precisando, antes, ser instruída por considerações teóricas adequadamente fundamentadas. Porque a relação com a prática não se esgota na simples negação do que é o efetivo, a própria teoria precisou se voltar de um modo muito particular para a realidade social, uma vez que tal negação deve ser engendrada nas contradições presentes nos processos reais. Nesse sentido, uma compreensão adequada do sistema capitalista foi fundamental para a orientação esclarecida da ação

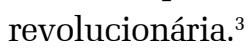

Isso significa que, diferentemente do socialismo utópico, Marx retira das próprias condições capitalistas existentes o movimento real de sua transformação. Para tanto, a tarefa teórica mais importante consiste em produzir um diagnóstico de época capaz de evidenciar as condições e os obstáculos para a orientação prática. O que Marx expõe em sua principal obra, $O \mathrm{ca}$ pital, consiste na tentativa de oferecer o melhor diagnóstico da sociedade capitalista de seu tempo. Esse diagnóstico possui dois momentos fundamentais em que se expõe, num mesmo processo imanente, a relação entre teoria e prática. Por um lado, os potenciais emancipatórios precisam estar presentes na sociedade capitalista, para que a justificação da transformação social não decorra de algum ponto de vista transcendente. Certamente que tais potenciais, ainda que existentes, precisam ser "libertados", já que, na sociedade capitalista, tais potenciais permanecem bloqueados. Por essa razão, Marx traz à tona o fato de que o capitalismo não cumpre o que promete, pois o princípio de reciprocidade, pressuposto numa sociedade baseada no intercâm-

${ }^{3}$ É por essa razão que “o comunismo”, dizem Marx e Engels, "não é, para nós, um estado que deve ser produzido, um ideal para o qual a realidade terá de se direcionar. Chamamos comunismo o movimento real que supera o estado presente. As condições desse movimento resultam do pressuposto atualmente existente" (Engels; Marx, 1990, p.35). bio de mercadorias, esconde uma oposição entre diferentes classes, oposição estabelecida na desigualdade constitutiva entre aquele que entra nas relações sociais como proprietário de mercadorias e aquele que possui como mercadoria apenas sua própria força de trabalho. Por outro lado, longe de simplesmente descrever imparcialmente o funcionamento do capital, a crítica da economia política mostra que o próprio capitalismo produz, de forma imanente, as condições de sua autodestruição, de onde decorrem tanto suas análises sobre as crises internas do sistema capitalista quanto sobre a possibilidade de uma ação revolucionária do proletariado.

Esse diagnóstico de época presente em $O$ capital expõe determinada forma de patologia social. $^{4}$ Em outros termos, podemos dizer que Marx expõe simultaneamente o diagnóstico histórico do capitalismo desenvolvido e a consequência patológica que a lógica capitalista impõe sobre os indivíduos. Segundo Marx, o capitalismo se caracteriza pelo fato de que suas relações sociais fundamentais são constituídas pelo trabalho, mais especificamente, pelo trabalho abstrato (Marx, 1998). Embora o trabalho seja também um processo para se criarem materialmente produtos, o aspecto do trabalho mais decisivo sob condições capitalistas consiste em determinar feições abstratas de relações sociais. O sistema capitalista incorpora o trabalho abstrato como uma forma de dominação social que mantém a função das estruturas objetivas e impessoais sobre as relações concretas dos indivíduos. Intrinsecamente à sua lógica reprodutiva, o capitalismo manifesta, assim, uma forma de patologia social (Postone, 1993, cap.4).

A crítica imanente, sobre a qual deve se debruçar a teoria, resulta de uma articulação desses diferentes fatores analisados. Trata-se de um diagnóstico de época ancorado a) na investigação histórica e categorial da lógica de funcionamento e reprodução do capitalismo; b) que lança luz sobre as determinações contraditórias ${ }^{4}$ Para uma apresentação geral da gênese do conceito de “pato-
logia” na tradição da teoria crítica, ver Honneth (2000, 2007). 
do sistema (criando intrinsecamente formas de patologia social); e c) que retira dos pressupostos do desenvolvimento do próprio sistema as condições sociais de sua superação, ou seja, da emancipação social. Para que todos esses fatores trabalhem conjuntamente na perspectiva da teoria, isso implica um tipo de crítica social autoreflexiva. "O ponto de partida da crítica", comenta Moishe Postone, "é imanente ao seu objeto social; ele está baseado no caráter contraditório da sociedade capitalista, o qual aponta para a possibilidade de sua negação histórica" ((Postone, 1993, p.140).

De acordo com tais considerações iniciais, é possível agora caracterizar a singularidade da teoria crítica com base em dois princípios. Segundo Marcos Nobre, "a orientação para a emancipação é o primeiro princípio fundamental" da teoria crítica (Nobre, 2004, p.32). Isso significa que o teórico não busca separar-se do objeto que estuda, não atribui a seus próprios procedimentos investigativos uma postura desinteressada e neutra, limitada à mera quantificação, classificação e comparação de fenômenos observáveis. $D e$ saída, o olhar do observador está inserido no próprio objeto estudado, a sociedade, e, com consciência do lugar que nela ocupa, a teoria lida de forma reflexiva com os próprios contextos em que é formulada e aplicada. A teoria também é um "sujeito" do momento histórico dentro de uma totalidade social que o comportamento crítico pretende transformar. Já o segundo princípio fundamental consiste no "comportamento crítico relativamente ao conhecimento produzido sob condições sociais capitalistas e à própria realidade social que esse comportamento pretende apreender." (2004, p.33). Se a perspectiva da emancipação não pode ser derivada de meras ideias, se não pode limitar-se a imagens ideais de condições de justiça e igualdade, então a teoria tem de ser capaz de apresentá-la como uma possibilidade real. Caso essa possibilidade não seja identificada na análise das condições existentes, a teoria ainda assim pode diagnosticar criticamente os obstáculos presentes à emancipação e suas respectivas patologias.

Ora, a teoria crítica precisou fazer um reexame do marxismo para poder repensar a relação entre teoria e prática. Nesse ponto, é natural que as circunstâncias históricas fossem determinantes. Como notou Martin Jay em sua excelente reconstrução da história do Instituto de Pesquisas Sociais, os intelectuais de esquerda da Alemanha, que ocupavam o centro do marxismo ocidental, estavam diante de um "dilema" que os forçava a reformular os diagnósticos apresentados pela tradição crítica ligada a Marx. Por um lado, considerando o inesperado sucesso da Revolução Bolchevique, eles poderiam se ligar ao Partido Comunista Alemão e dar continuidade às estratégias lideradas por Moscou para combater o espírito liberal e "burguês" que animava a República de Weimar. Por outro lado, seria possível simplesmente apoiar os socialistas moderados e se orientar pela realização progressiva da democracia, evitando, assim, a via da revolução. Entretanto, "um terceiro curso de ação", lembra Martin Jay,

resultou quase inteiramente da ruptura radical dos pressupostos marxistas, uma ruptura acarretada pela guerra e por suas consequências. Essa última alternativa foi o reexame minucioso das bases da teoria marxista, na dupla esperança de explicar os erros do passado e preparar a ação do futuro. Isso deu início a um processo que conduziu, inevitavelmente, às regiões mal iluminadas do passado filosófico de Marx (Jay, 2008, p.39).

Ao me ater à posição exemplar de Horkheimer entre tais intelectuais, esse dilema faria implodir aquelas condições pressupostas por Marx para que o movimento real de emancipação pudesse ser reafirmado ainda no tempo presente. Diferentemente das posições mais dominantes no interior do marxismo,

Horkheimer não considerava mais possível, em vista das novas condições históricas, continuar sustentando que o proletariado seria a única força política interna ao próprio sistema, que seria portadora da destruição do capitalismo e da instauração do socialismo. Em razão de seu diagnóstico do tempo, já não considerava possível sustentar uma união entre teoria e prática nos 
termos em que havia sido pensada pelo marxismo de seu tempo (Nobre, 2008, p.37).

A consequência mais radical desse novo diagnóstico, portanto, consistiu em não se encontrar mais os pressupostos efetivos para que o proletariado pudesse continuar a ser considerado o portador universal da emancipação. A passagem do capitalismo concorrencial para o monopolista, o enriquecimento (e não "empobrecimento", como havia previsto Marx) da classe trabalhadora e a ascensão do Nazismo impeliam os teóricos do Instituto de Pesquisa Social a um novo diagnóstico de época.

Em seu texto "Teoria tradicional e teoria crítica", provavelmente um dos mais importantes de todo o período da década de 1930, Horkheimer apresenta uma alternativa para se pensar criticamente a relação entre teoria e prática (Horkheimer, 1975). Essa alternativa ficou conhecida como o materialismo interdisciplinar, um trabalho exercido em conjunto por diferentes perspectivas teóricas - filosofia, sociologia, psicanálise, economia, direito etc. - que se voltavam para as investigações sobre a sociedade, adotando aquela atitude da teoria com interesses práticos acima aludida. Desse modo, o ponto de vista "privilegiado" a partir do qual seria possível diagnosticar a sociedade contemporânea não corresponderia mais àquele do proletariado, como pretendeu Lukács, mas seria atribuído agora à postura crítica da teoria. "Por mais que sofra na própria carne o absurdo da continuação da miséria e do aumento da injustiça”, comenta Horkheimer,

a diferenciação de sua estrutura social estimulada de cima, e a oposição de interesses pessoal e de classe, superada apenas em momentos excepcionais, impede que o proletariado adquira imediatamente consciência disso (1975, p.142-143).

Logo, a tomada de consciência das contradições sociais (e das patologias) concerne a um materialismo interdisciplinar. Porém isso significa ainda que, no rol de teorias tradicionais especializadas, nenhuma delas assume posição de destaque, capaz de ver, a partir de sua própria especialização, o todo social. A totalidade das relações sociais só pode ser avaliada criticamente levando-se em consideração os diferentes aspectos da sociedade iluminados por cada uma das áreas do saber especializado. Supera-se, assim, a particularidade das ciências tradicionais em virtude do interesse pela compreensão da totalidade (Held, 1980; Jay, 1984, 2008).

Esse materialismo interdisciplinar não apenas produz como também é fruto do novo diagnóstico de época que a teoria procura formular. Com ele, deixam de ser porto seguro não apenas o proletariado como portador da emancipação, mas também algumas conquistas da modernidade que, em um momento posterior da renovação do diagnóstico, serão paradoxalmente esvaziadas de seu sentido crítico. A teoria crítica pretende superar as verdades incrustadas no liberalismo, ao afirmar, acompanhando a esteira da crítica de Marx, que as concepções morais e políticas dos indivíduos, sua autonomia moral etc. resultam antes de uma sociedade de sujeitos econômicos independentes. Porém a autonomia e a independência do indivíduo, sobretudo sob condições de um capitalismo monopolista, deixaram de existir, ou seja, "o indivíduo deixou de ter um pensamento próprio" (Horkheimer, 1975, p.159). A teoria não poderia, desse modo, ancorar-se na autonomia dos sujeitos e se voltar para si mesma de modo reflexivo, isto é, mantendo a postura crítica da teoria como condição de possibilidade de negação dos males da sociedade capitalista.

Nesse sentido, a existência de uma postura crítica da teoria mantém presente, juntamente com seus diagnósticos, a possibilidade mesma de que a transformação da ordem social vigente seja efetiva e encontre condições para o "êxito histórico". Aquele princípio de orientação para a emancipação, embora não esteja ancorado imediatamente na base de uma "práxis esmerada", como diz Horkheimer, tem de ser medido no quadro desse novo materialismo interdisciplinar, segundo seu "interesse na transformação". Esse 
interesse, segue Horkheimer, "deve ser informado e dirigido pela própria teoria, ao mesmo tempo em que exerce uma ação sobre ela" (1975, p.161). Fica evidente, agora, que a crítica social (e toda provável orientação emancipatória vislumbrada) passa a depender necessariamente do esforço em se produzir o melhor diagnóstico possível. A abrangência, a profundidade e a adequação de tal diagnóstico estão sujeitas ao trabalho interdisciplinar igualmente exigente. Sem uma teoria social que ancore sua postura crítica no diagnóstico produzido por um materialismo interdisciplinar, toda orientação emancipatória corre o risco de se perder no mero normativismo.

Porque, na teoria crítica, não há oposição entre verdade e história: a verdade passa a ter um núcleo temporal fundamental. ${ }^{5} \mathrm{O}$ que leva à necessidade de reformular os diagnósticos, como aponta explicitamente o Prefácio do livro de Horkheimer e Adorno de 1944:

Embora tivéssemos observado há muitos anos que, na atividade científica moderna, o preço das grandes invenções é a ruína progressiva da cultura teórica, acreditávamos de qualquer modo que podíamos nos dedicar a ela na medida em que fosse possível limitar nosso desempenho à crítica ou ao desenvolvimento da temáticas especializadas. Nosso desempenho devia restringir-se, pelo menos tematicamente, às disciplinas tradicionais: à sociologia, à psicologia e à teoria do conhecimento [...] Os fragmentos que aqui reunimos mostram, contudo, que tivemos de abandonar aquela confiança (Adorno; Horkheimer, 1985, p.11).

Esses fragmentos sugerem que o projeto emancipatório diagnosticado no texto anterior de 1937 estaria temporariamente suspenso, pois as condições emancipatórias existentes na sociedade estavam obstruídas, incluindo aquelas condições que tornavam possível o próprio empreendimento de uma teoria interdisciplinar reflexiva com interesses práticos.

O que o livro Dialética do esclarecimento diagnostica (tendo como horizonte teórico os trabalhos do economista Friedrich Pollock sobre o

5 "Se a verdade tem, de fato, um núcleo temporal, então o conteúdo histórico torna-se, em sua plenitude, um momento integral dessa verdade”. Adorno. (2003, p.26). capitalismo de Estado) consiste, grosso modo, no império da razão instrumental exercendo seu domínio sobre todas as esferas da sociedade. As patologias da modernidade, produzidas pela imposição hegemônica da razão instrumental, manifestam-se nos campos da moral, da ciência e da arte. É resultado de uma economia capitalista monopolista, que conta com ampla intervenção do Estado sobre a vida dos indivíduos e cria as condições favoráveis para a implementação de um mundo totalmente administrado ${ }^{6}$. Encontrase obstruída, portanto, toda a possibilidade de emancipação e, por sua vez, a própria relação entre teoria e práxis (Horkheimer, 2008, p.136). Do ponto de vista propriamente político, há, em Adorno e Horkheimer, um "período de hibernação" que se manteve por muito tempo sob os efeitos da Dialética do esclarecimento. Embora desde sempre ambos os autores mantivessem particularidades que caracterizavam a teoria elaborada por cada um separadamente - posições independentes que perduraram posteriormente -, a relação entre teoria e prática continuou, em grande medida, bloqueada pelos diagnósticos reiteradamente "negativos."

${ }^{6}$ Que o diagnóstico presente no livro Dialética do esclarecimento seja condicionado pela história e, portanto, pela forma histórica adotada pelo capitalismo tardio não parece ser algo indiscutível. Não apenas em muitas passagens do texto, mas considerando ainda a exposição dos ensaios e a temática central que anima o livro ("o mito já é esclarecimento e o esclarecimento acaba por reverter à mitologia”), esse diagnóstico lança mão de uma série de elementos a-históricos. Obviamente, não havia capitalismo monopolista na época de Ulisses, porém já na proto-história surgem centelhas da razão instrumental. Há assim, por exemplo, uma disparidade entre o capítulo sobre a indústria cultural (em que a passagem do capitalismo liberal para o monopolista é explicitamente sublinhado) e os demais capítulos contidos no livro. Para uma crítica desse modo de exposição da Dialética do esclarecimento, ver Habermas, J. (2002, cap. 5).

${ }^{7}$ Horkheimer se aproximou de uma "teologia negativa" e de uma concepção filosófica pessimista, cuja postura negativa permitia uma forma continuada de teoria crítica. (Ramos, 2008, p.99-113). Já Adorno, por sua vez, nunca deixou de admitir, assumindo o paradoxo, que a teoria assumiria a atitude crítica obstruída por uma práxis que, segundo o autor, tornou-se “cega”. "A práxis - e eu também não me envergonho de afirmar isso com tamanha radicalidade - se fincou em grande medida na teoria, ou seja, nas esferas da reflexão renovada sobre a possibilidade de um comportamento correto". Adorno (1996, p.13). Sobre a relação entre o diagnóstico da Dialética do esclarecimento e aquele desenvolvido posteriormente por Adorno, ver Nobre (1998). Para uma visão não apenas global, mas comparativa da obra tardia de Horkheimer e Adorno, ver Demiroviæ (1999). 
Cabe notar que não há um diagnóstico único por detrás da variedade de autores da teoria crítica. Por motivos de espaço, privilegiei até aqui apenas os traços principais daqueles diagnósticos mais comuns atribuídos ao "círculo interno" da primeira geração da teoria crítica (Honneth, 1999), sobretudo limitando-me a certos passos de Horkheimer e Adorno. Mas a desilusão com a luta de classes e com o paradigma revolucionário ou mesmo a recusa em admitir saídas democráticas para os dilemas presentes na articulação entre teoria e prática, não foram seguidas por todos os autores naquele mesmo momento. A história da teoria crítica é marcada por uma concorrência entre os diagnósticos de época, e podemos avaliá-los como mais ou menos adequados à crítica da sociedade (Melo, 2009b). Para ficarmos com apenas um exemplo, Franz Neumann, considerado membro do "círculo externo" da teoria crítica, jamais abdicou da luta política e da ação do proletariado como caminho para a emancipação social. Contudo, certo diagnóstico do capitalismo monopolista, aliado à sua reconstrução do desenvolvimento da tradição do direito ocidental, permitiu a Neumann destacar o potencial emancipatório do direito no âmbito da teoria crítica. A despeito do que ocorria simultaneamente na Alemanha nacional-socialista, Neumann deu especial atenção também aos acontecimentos políticos na Inglaterra com a entrada do proletariado inglês no Parlamento (Neumann, 2011; Rodriguez, 2008). Essa formulação nos abre diferentes e novas perspectivas críticas, relativizando o diagnóstico de Horkheimer e Adorno, presos aos acontecimentos ligados à ascensão do Nazismo e à experiência totalitária do capitalismo de Estado.

\section{EXCURSO: a emancipação pelo trabalho nos paradigmas revolucionário e reformista}

Vimos acima que a fundação da teoria crítica esteve atrelada à possibilidade de se encontrar uma saída no campo do marxismo que evi- tasse a ortodoxia do socialismo soviético e uma provável resignação de uma postura social-democrata que flertava, cada vez mais, com o liberalismo. Essa tomada de posição alternativa abriu a possibilidade de se questionarem os paradigmas revolucionário e reformista que marcaram teórica e praticamente o imaginário do socialismo quase em sua totalidade. Esse questionamento, ao menos por princípio, não implicava abrir mão de uma teoria crítica orientada para a emancipação. Essa tentativa de superar a clássica oposição que se estabeleceu historicamente entre o marxismo revolucionário e concepções reformistas denota um dos aspectos mais centrais da teoria crítica (Melo, 2009b). Contudo, o modo como essa superação foi formulada teoricamente entre os diversos autores da teoria crítica nem sempre levou a soluções mais adequadas para a renovação dos modelos críticos. Pois essa tarefa dependia, antes, de se questionar um elemento nuclear da teoria da emancipação de Marx, recolocado pelas concepções revolucionária e reformista, a saber, o paradigma produtivista e o modelo de ação baseado no trabalho. Foi no conceito de trabalho que Marx pôde encontrar o conteúdo normativo inscrito nos processos efetivos e mostrar ser preciso libertá-lo de suas formas sociais reificadas para restituí-lo como autoatividade produtiva.

Desde Marx, já tomamos consciência dos efeitos colaterais disfuncionais e perigosos de uma sociedade que se moldara profundamente pelo trabalho abstrato, ou seja, trabalho remunerado, regido pelo mercado e organizado socialmente na forma capitalista. A crítica da economia política mostrou que o sistema econômico burguês criado impossibilitava a realização da liberdade e da igualdade no interior de sua lógica reprodutiva. Porém, se, por um lado, o processo de autovalorização do capital retirava dos indivíduos a capacidade de uma ação autônoma, pois submetia todos os âmbitos da vida ao seu próprio imperativo, o paradigma produtivista, por outro lado, caracterizaria também a condição de superação dessa situação de opressão e da restituição da própria 
autonomia. Marx entendeu a forma de socialização não-capitalista segundo categorias do trabalho, ou seja, a capacidade que um sujeito socializado possui para dispor dos meios e dos processos materiais que configuram sua própria vida. Nessa linha de interpretação, a autonomia, ou autoatividade produtiva dos indivíduos ou das classes só poderia ser alcançada quando os trabalhadores se apropriassem coletivamente da totalidade da produção, identificando, assim, emancipação e desenvolvimento das forças produtivas (Lange, 1980). Em suma, afirmar que a crítica radical empreendida por Marx permanecia fixada dentro do horizonte da utopia da sociedade do trabalho significava que a revolução do capitalismo visava à possibilidade de constituição de uma reorganização social fundada novamente no trabalho, mesmo que de outro tipo. Foi exatamente essa "visão utópica que penetrou o movimento operário e ainda nutre a ideologia do trabalho compartilhada pelas esquerdas clássicas" (Gorz, 2003, p.33).

Os debates em torno dos ideais emancipatórios socialistas foram articulados, sobretudo, pela antinomia da revolução ou reforma do capitalismo. Muitos autores reconhecem que essa antinomia entre comunismo revolucionário e reformismo social-democrata, que dominou os termos do debate sobre a esquerda no século XX, estava situada nesse campo. Em linhas gerais, os comunistas acusavam os reformistas social-democratas por terem traído os interesses da classe trabalhadora ao abandonarem o fim último da transformação revolucionária do capitalismo. Os social-democratas procuravam justificar caminhos alternativos para se imaginar uma sociedade na qual se pudesse combinar a intervenção do Estado e o mercado com a finalidade de alcançar uma redistribuição mais centralizada de recursos e prover, assim, mais oportunidades para a vida. Contudo, apesar dessa antinomia, ambos se preocupariam prioritariamente com os melhores meios e estratégias de se alcançar uma distribuição socialmente mais justa e igual, mas não haveria um desacordo sobre o próprio fim último a ser alcan- çado, ou seja, à imagem de uma sociedade desigual, configurada sob os efeitos negativos e injustos do capitalismo, se opunha aquela de uma sociedade emancipada, na qual reinaria a disposição mais justa e igualitária sobre os produtos do trabalho e as condições de sua implementação. ${ }^{8}$

Para os revolucionários, a restituição da autonomia alienada sob condições capitalistas dependeria antes da transformação radical do trabalho heterônomo em trabalho autônomo, justificando, assim, tanto as bases do argumento marxista ortodoxo, segundo o qual a emancipação decorreria das determinações estruturais do desenvolvimento capitalista, como a substituição da constituição de uma comunidade de livres e iguais pela auto-organização holista de trabalhadores associados, libertos do fetiche do capital. Além disso, o próprio conceito de práxis política, central para a ideia de uma autoemancipação do proletariado, seria concebido no processo revolucionário como epifenômeno das relações econômicas, limitando a atividade autônoma da classe trabalhadora à autoatividade produtiva assim como fundindo e homogeneizando a autodeterminação política, de sorte que o proletariado fosse constituído somente como uma afirmação subjetiva da lógica reprodutiva do próprio capital.

A orientação reformista, por sua vez, abdicou do socialismo científico e das pretensões revolucionárias, estabelecendo seu programa político com base em reformas político-administrativas centralizadas na universalização dos direitos civis. O núcleo normativo do reformismo social-democrata consistia, portanto, na transformação do trabalho considerado mercadoria em trabalho entendido como base de um direito de cidadania industrial. Contudo, as conquistas obtidas pelo Estado social confinavam, paradoxalmente, a democracia à instância meramente administrativa que determinava o plano socialdemocrata, engessando a autodeterminação política dos cidadãos no papel de meros clientes da

\footnotetext{
Essa abordagem centralizada na questão da revolução ou reforma do capitalismo é predominante mesmo em historiadores tais como Sasson (1996), Eley (2002) e também Rosemberg (1999).
} 
burocracia dos programas de bem-estar e no de consumidores de bens de massa. As orientações revolucionárias e reformistas levaram adiante o projeto de uma democracia radical apenas parcialmente, reduzindo tradicionalmente a orientação emancipatória ao processo de realização da utopia de uma sociedade do trabalho.

\section{SENTIDOS DA EMANCIPAÇÃO: superando o paradigma produtivista}

Uma autorreflexão crítica sobre as orientações emancipatórias vinculadas aos diferentes diagnósticos de época obrigou a teoria crítica a rever certas limitações de pressupostos comuns responsáveis por manter suas inspirações teóricas e intuições normativas predominantemente voltadas a um sentido de emancipação em particular. A primeira geração da teoria crítica começou a desconfiar do potencial emancipatório inscrito na categoria do trabalho e denunciou a justificação positiva que o papel das forças produtivas interpretadas como razão instrumental exercia no modelo de Marx e do marxismo. Entretanto, os diagnósticos negativos apresentados pela primeira geração deixaram uma lacuna em relação ao ponto de vista prático-emancipatório, de modo que não foi possível preencher o lugar ocupado pelo trabalho. Ou melhor, embora mantivessem o horizonte negativo do trabalho social para a produção de seus diagnósticos, a primeira geração não preencheu com outro conteúdo normativo aquele aspecto positivo que o trabalho anteriormente também possuía para o sentido emancipatório.

A crítica ao paradigma produtivista implicaria duas possíveis interpretações da história dos efeitos presentes em uma autocrítica do materialismo histórico. Primeiramente, na medida em que "esse pensamento procurou criticar a metafísica burguesa do trabalho", comenta Stefan Breuer, "também se movimentou no mesmo espaço homogêneo, abrangente e tradicional que a ideologia burguesa havia produzido"
(Breuer, 1977, p.11). A teoria social crítica recepcionaria essa continuidade de uma teoria da revolução presa ao conceito de trabalho como “crítica de falsas promessas" (1977, p. 240). O trabalho não teria potencial emancipatório, mas se apresentaria sempre como dominação, pois,

segundo sua lógica interna, tal seria a consequência dessa interpretação, a análise da forma do valor não se consolidou em uma teoria da revolução, mas antes no conceito de sua impossibilidade: o que ela mostrou foi a submissão da sociedade sob a generalização de suas relações abstratas (p.17-18).

Em segundo lugar, a interpretação marxista ortodoxa, de acordo com a qual a democracia consistiria em mero reflexo da base econômica, dificultou uma recepção dos textos de Marx na qual a teoria da emancipação não fosse diretamente determinada pelo paradigma produtivista. Evitar essa sobredeterminação consistiria numa das principais tarefas de uma nova teoria crítica, uma vez que a teoria das classes

exclui perigosamente a possibilidade [...] de poder haver outros modos de dominação que não as relações de classe socioeconômicas, outros princípios de estratificação além de classe (nacionalidade, raça, status, sexo, etc.), outros modos de criação histórica e de interação que não o trabalho e a práxis revolucionária, outras fontes de motivação para a orientação da ação social, outras formas de interação política (participação) que não relações hierárquicas de poder, e outras maneiras de contestar a sociedade capitalista que não as lutas de classe em torno de necessidades radicais que emergem na dialética do trabalho (Cohen, 1982, p.193).

Para alguns autores, apenas outra recepção da obra de Marx permitiria encontrar, já em seus próprios textos, possíveis saídas para o impasse criado pelo paradigma produtivista como orientação emancipatória e superar a determinação da política como mero epifenômeno das relações econômicas (Melo, 2009a).

A tarefa da autorreflexão da crítica social consistiria, assim, em "superar o paradigma produtivista, sem abrir mão das intenções do marxismo ocidental" (Habermas, 1985, p.217). Na formulação de Marcos Nobre, "as aporias da 
vertente 'de esquerda' do projeto moderno são índice da necessidade de reformular os termos do próprio projeto" (Nobre, 1998, p.183). Essa reformulação, tão importante para a fundamentação das orientações teóricas e práticas das novas lutas emancipatórias, requer um acerto de contas com o paradigma produtivista. Axel Honneth sintetizou essa ideia ao lembrar que a "fraqueza teórica" do "círculo interno" da primeira geração da teoria crítica residiria exatamente em manter seu programa vinculado ao quadro de um "reducionismo funcionalista" em que "apenas os processos sociais suscetíveis de assumir funções na reprodução e na expansão do trabalho social podem encontrar um lugar nele” (Honneth, 1999, p.516). Porém, "os impulsos antifuncionalistas [...] chegaram à autoconsciência teórica” (p.538), justamente na teoria apresentada por um autor da segunda geração, Jürgen Habermas, e, desde então, se tornaram o novo quadro de referência de grande parte dos novos modelos de teoria crítica para uma concepção diversa da sociedade, a qual precisaria evitar, por um lado, aquela aporia que uma "dialética do esclarecimento" criaria para a relação entre teoria e prática e para a possibilidade de justificar normativamente uma perspectiva para a própria atitude crítica e, por outro lado, abandonar a utopia de uma sociedade do trabalho cujas energias utópicas teriam se esgotado.

Partindo das críticas propostas pela teoria social contemporânea à categoria do trabalho, podemos notar que o elemento crítico e emancipatório que perpassava o desenvolvimento das sociedades modernas consiste não na centralidade da gênese e no conjunto do processo de autovalorização do capital privilegiado pelo paradigma produtivista, mas no resgate do projeto de uma democracia radical, ou seja, no resgate de um projeto de autodeterminação e de autorrealização pelo qual os próprios cidadãos seriam capazes de se organizar de forma livre e igual. Nesse sentido, se a questão da democracia, muitas vezes, se tornou um problema derivado na teoria e na prática de revolucionários e reformistas, isso não ocorreu porque estaria intima e necessariamente inscrito, nos pressupostos e motivações de suas concepções, um déficit democrático, mas antes porque a plena realização da liberdade e da igualdade permaneceu vinculada à utopia da sociedade do trabalho. Desse modo, a questão da democracia precisaria ser recuperada na produção renovada dos diagnósticos de época.

A bancarrota do socialismo de Estado e os novos movimentos sociais ocorridos no leste europeu foram sintomáticos para se repensarem não apenas os significados históricos, os limites dos estímulos teóricos e as orientações normativas da esquerda, mas, principalmente, para a reconstrução de um novo quadro de problemas em que a arena democrática estabelece os contornos de um novo diagnóstico ligado à política e ao direito. Certamente, a esquerda não-comunista - que não se culpou pela falência de um socialismo de Estado que ela sempre criticou - não deveria "agir como se nada tivesse acontecido" (Habermas, 1990, p.188). Os novos movimentos sociais, que respondiam às desastrosas consequências do estatismo social sobre diferentes formas de vida, formas de participação, solidariedade e autonomia, pretendiam tornar o Estado social mais reflexivo ao constituírem demandas pela conquista de direitos e garantias individuais, passando pela rediscussão de problemas de redistribuição econômica e compensações sociais, até reivindicações por reconhecimentos de identidades coletivas marginalizadas, etc. Tais acontecimentos indicariam a possibilidade de superação da antinomia clássica entre reforma ou revolução, pois acirravam a relação entre democracia radical e Estado de direito e lançavam nova luz à pluralidade de sentidos que a teoria crítica atribuiria hoje aos seus ideais emancipatórios (Arato; Cohen, 1995).

O esgotamento da utopia em face dos obstáculos da economia e do poder político pôs de lado não a orientação emancipatória como tal, mas suas determinações totalizantes. A utopia da sociedade do trabalho parece ter ficado para 
trás, mas não o ímpeto de formas de vida que reagem e lutam pelo seu espaço de autonomia, mostrando que a emancipação não tem apenas um sentido, mas é perpassada por uma pluralidade de perspectivas. Emancipação significa, portanto, "libertação de energias políticas paralisadas" (Habermas, 1990, p.93). E as manifestações de revolta não são inventadas pelo teórico. Elas são provocadas estruturalmente pelas desigualdades produzidas pelo mercado e pelo Estado ou pela dinâmica dos conflitos em torno de valores, do pluralismo social e cultural, dos fenômenos de intolerância, injustiça etc. (Melo, 2009b).

Essa emergência de uma pluralidade de movimentos sociais, mobilizações políticas e manifestações de revolta, que permitiram que os diversos sentidos da emancipação fossem articulados com o projeto de uma democracia radical, tornou necessário estreitar o vínculo fundamental entre uma teoria crítica da sociedade e o quadro de problemas da teoria política, voltados aos estudos da esfera pública e da sociedade civil, da democracia e do direito. Muitos autores da nova geração da teoria crítica enfatizaram que só seria possível atualmente dar continuidade ao projeto crítico-emancipatório dessa tradição de pensamento se os temas da política, do direito e da democracia fossem seriamente levados em consideração para que a formulação dos novos diagnósticos de época fosse compatível com um conceito de política radical, participativo e pluralista. ${ }^{9}$ Pois a cultura política estudada nessa, digamos, teoria crítica da democracia, formada por um público capaz de se mobilizar diante dos riscos da perda de liberdade, torna presente o ideal de um Estado democrático de direito na medida em que o vincula necessariamente aos processos políticos de legitimação ar-

${ }^{9}$ Para citar apenas dois exemplos: "A negligência quanto a uma tal teoria política e democrática é um dos principais pontos cegos da teoria crítica da Escola de Frankfurt". (Benhabib, 1986, p.347). "A teoria crítica não pode mais manter seus propósitos práticos sem uma teoria política”, uma vez que "a crítica da razão funcionalista precisa ser complementada por uma teoria da democracia” (Arato; Cohen 1989, p.493). ticulados com as lutas sociais e com uma concepção de democracia sensível às manifestações da esfera pública (Habermas, 1992).

Portanto, a dimensão do conflito classicamente considerado pela esquerda entre capital e trabalho e os remédios redistributivos vislumbrados não podem mais pretender representar as condições políticas, sociais, econômicas e culturais a partir das quais podemos diagnosticar as possibilidades imanentes para a realização de mudanças nos contextos de nossa época. Na verdade, essas condições - chamadas sintomaticamente por alguns de "pós-socialistas" dificultam uma visão historicamente progressista para interpretarmos a natureza, muitas vezes pouco transparente, das novas orientações emancipatórias. Porém, como esclarece Nancy Fraser, embora inviabilizem um diagnóstico atual que aponte para um grande e único projeto emancipatório, tais condições "pós-socialistas" constituem o horizonte inevitável de toda teoria política contemporânea (Fraser, 1997). E não cabe à teoria crítica preencher a lacuna criada pela ausência desse projeto e reescrever sua história, mas sim investigar criticamente essa proliferação de conflitos e reconstruir seus sentidos. A solução do conflito entre capital e trabalho eliminaria também a desigualdade de gênero, a discriminação racial ou a homofobia? O diagnóstico que apoia esse panorama contemporâneo não precisa ser produzido somente se considerarmos as esferas mobilizadas por tais conflitos, as quais não se limitam à economia, mas abrangem investigações amplas sobre o direito e a democracia?

Parte do projeto de renovação dos modelos críticos implica não pensar mais os movimentos por emancipação a partir do conceito de totalidade, posto que a autodeterminação política é conquistada apenas no interior de um processo de circulação do poder em que se luta pela integridade da autonomia das formas de vida, pelos espaços de autorrealização e conquistas de direitos em face da pressão exercida pelos imperativos da economia e as constrições do sistema político. A teoria crítica passa a reconstruir, as- 
sim, a pluralidade dos movimentos por emancipação, em torno da reivindicação de direitos legítimos mobilizados por lutas por reconhecimento em que se explicitam a interdependência e as relações recíprocas entre política e direito (Taylor, 2000; Honneth, 2003; Habermas, 1997). A afirmação radical da autodeterminação política evidenciada por tais movimentos envolvem demandas por direitos políticos, sociais e culturais ,assim como maior participação nos processos de formação política da opinião e da vontade e nos procedimentos democráticos de deliberação pública (Bohman, 1996; Melo; Werle, 2007; Melo, 2011). Compreender essa complexa dinâmica sem perder de vista a orientação para a emancipação constitui a tarefa crucial para a renovação dos modelos críticos.

\section{CONSIDERAÇÕES FINAIS}

O esforço para se mobilizar uma teoria social interdisciplinar com o intuito de produzir um diagnóstico crítico de nossa época está no cerne das preocupações daqueles que pretendem fazer teoria crítica. Porque não há um diagnóstico definitivo, não é apenas no que diz respeito aos aspectos metodológicos que temos de lidar com um elemento falibilista que habita o empreendimento crítico. Os grandes paradigmas emancipatórios, se pretendiam resultar de uma teoria crítica bem fundamentada, também estariam submetidos, cedo ou tarde, a um reexame crítico. O quadro que procurei esquematizar aqui, partindo principalmente daqueles autores que se ocupam de renovar criticamente seus diagnósticos, não nos leva a concluir pela impossibilidade de dar continuidade aos interesses crítico-emacipatórios. Trata-se de apontar, antes, para o vínculo necessário entre os potenciais ou os obstáculos à emancipação diagnosticados e um enorme esforço interdisciplinar empregado no conhecimento dos mais diversos processos, práticas e instituições que compõem nosso objeto social. Não há orientação eficaz para a ação sem uma teoria adequada que primeiramente descreva e compreenda os fenômenos reais da sociedade. Se, para Marx, essa interdisciplinaridade estava arranjada em torno da economia política, atualmente a produção de um diagnóstico pretensamente correto parece depender de uma composição disciplinar diferente. Contudo, a mera descrição, limitada à positividade do objeto social, não permite evidenciar os interesses práticos que formam parte crucial da realidade. Porém antecipar o que seria considerado emancipatório sem apresentar a gênese dos conflitos e de suas respectivas pretensões práticas consiste em fazer o exato oposto daquilo que seria exigido de uma teoria crítica, pois ela não pode senão limitar-se a reconstruir as condições de acordo com as quais os próprios concernidos procuram restituir sua autonomia. Assim como não há teoria crítica sem a renovação de seus modelos críticos, não há como oferecer novos diagnósticos sem entendermos os processos efetivos a partir dos quais a orientação emancipatória ancora seus sentidos.

(Recebido para publicação em 18 de maio de 2011) (Aceito em 19 de julho de 2011)

\section{REFERÊNCIAS}

ADORNO, T. W. Probleme der moralphilosophie. Frankfurt: Main: Suhrkamp, 1996.

. O ensaio como forma. In: . Notas de literatura I. Trad. Jorge de Almeida. São Paulo: Editora 34, 2003.

; HORKHEIMER, M. Dialética do esclarecimento. Trad. Guido Antonio de Almeida. Rio de Janeiro: Jorge Zahar, 1985

ARATO, A : COHEN, J. Politics and the reconstruction of the concept of civil society. In: HONNETH, A. et al (Org.) Zwischenbetrachtungen: im prozess der aufklärung. Frankfurt; Main: Suhrkamp, 1989

Civil society and political theory. Cambridge: The MIT Press, 1995. Disponível em: www amazon.com/ Society-Political-Studies-Contemporary-Thought/ dp/ 0262531216 \#reader_0262531216

BENHABIB, S. Critique, norm, and utopia. A study of the foundations of critical theory. New York: Columbia University Press, 1986.

BOHMAN, J. Public deliberation: pluralism, complexity, and democracy. Cambridge: The MIT Press, 1996.

BREUER, S. Die krise der revolutionstheorie. Frankfurt; Main: Syndikat, 1977. 
COHEN, J. Class and civil society: the limits of marxian critical theory. Massachussets: University of Massachussets Press, 1982.

DEMIROVIÆ, A. Der nonkonformistische intellektuelle: die entwicklung der kritischen theorie zur Frankfurter Schule. Frankfurt; Main: Suhrkamp, 1999.

DRAPER, H. Karl Marx's theory of revolution IV: critique of other socialisms. New York: Monthly Review Press, 1990.

ELEY, G. Forging democracy: the history of the left in Europe, 1850-2000. Oxford: Oxford University Press, 2002.

ENGELS, F; MARX, K. Deutsche ideologie. In: Marx-Engels Werke. Band 3. Berlin: Dietz Verlag, $19 \overline{90 .}$

FRASER, N. Justice interruptus: critical reflections on the "postsocialist" condition. New York: Routledge, 1997.

GORZ, A. Metamorfoses do trabalho: crítica da razão econômica. Trad. Ana Montoia. São Paulo: Annablume, 2003.

HABERMAS, J. Ein Interview mit der New Left Review. In: Die neue unübersichtlichkeit. Frankfurt; Main: Suhrkamp, 1985.

Die nachholende revolution und linker revisionsbedarf: was heißt sozialismus heute?: was heißt sozialismus heute?. In: Frankfurt; Main: Suhrkamp, 1990a.

Interview mit hans Peter Krüger. In: . Die nachholende revolution. Frankfurt; Main: Suhrkamp, $1990 \mathrm{~b}$.

Kampf um anerkennung im demokratischen rechtsstaat. In: . Die einbeziehung des Anderen. Frankfurt; Main: Suhrkamp, 1997. 1998.

. Faktizität und geltung. Frankfurt; Main: Suhrkamp,

O discurso filosófico da modernidade. Trad. Luiz Repa e Rodnei Nascimento. São Paulo: Martins Fontes, 2002.

HELD, D. Introduction to critical theory: Horkheimer to Habermas. Los Angeles: University of California Press, 1980.

HONNETH, A. Teoria crítica. In: GIDDENS, A.; TURNER, J. (Org.) Teoria social hoje. Trad. Gilson Cardoso de Souza. São Paulo: UNESP, 1999

Pathologien des sozialen. Trad. Und Aktualität der Sozialphilosophie. In: HONNETH, A. Das Andere der gerechtigkeit. Frankfurt; Main: Suhrkamp, 2000.

. Luta por reconhecimento: a gramática moral dos conflitos sociais. Trad. Luiz Repa. São Paulo: Editora 34, 2003.

Pathologien der vernunft: geschichte und gegenwart der kritischen theorie. Frankfurt: Main: Suhrkamp, 2007

HORKHEIMER, M. Teoria tradicional e teoria crítica. In: Benjamin, Horkheimer, Adorno, Habermas. São Paulo: Abril Cultural 1975. (Coleção os pensadores, v.48).

Zur Kritik der instrumentellen vernunft. In: HORKHEIMER, M. Gesammelte schriften, Bd.6. Frankfurt; Main: Suhrkamp, 2008.
JAY, M. Marxism and totality: the adventures of a concept from Lukács to Habermas. Los Angeles: University of California Press, 1984.

A imaginação dialética: história da escola de Frankfurt e do Instituto de Pesquisas Sociais (1923-1950). Trad. Vera Ribeiro. Rio de Janeiro: Contraponto. 2008.

LANGE, M.. Das Prinzip Arbeit. Frankfurt; Main: Suhrkamp, 1980.

LICHTHEIM, G. Marxism: an historical and critical study. New York: Praeger Publischer, 1965.

The origins of socialism. New York: Praeger Publischer, 1969.

LUKÁCS, G. História e consciência de classe. Trad. Rodnei Nascimento. São Paulo: Martins Fontes, 2003.

MARX, K. Das Kapital.. In: Marx-Engels Werke. Bd 23. Berlim: Dietz Verlag. 1998. v.1

MELO, R. A ampliação do conceito do político: para uma outra recepção da teoria crítica de Marx. Cadernos de Filosofia Alemã XIII, São Paulo, USP, n.13, 2009a.

. Sentidos da emancipação: para além da antinomia revolução versus reforma. 2009. Tese (Doutorado) - Faculdade de Filosofia e Ciências Humanas da Universidade de São Paulo. 2009b.

O uso público da razão: pluralismo e democracia em Jürgen Habermas. São Paulo: Loyola, 2011.

; WERLE, D. (Org.) Democracia deliberativa. São Pauก: Singular/Esfera Pública, 2007.

NEUMANN, F. O império do direito: teoria política e sistema jurídico na sociedade moderna. Trad. Rúrion Melo. São Paulo: Quartier Latin, 2011.

NOBRE, M. A dialética negatva de Theodor W. Adorno. São Paulo: Iluminuras, 1998.

. Teoria crítica. Rio de Janeiro: Jorge Zahar, 2004.

Max Horkheimer: a teoria crítica entre o nazismo e o capitalismo tardio. In: NOBRE, M. (Org). Curso livre de teoria crítica. Campinas: Papirus, 2008.

POSTONE, M. Time, labor and social domination: reinterpretation of Marx's critical theory. Cambridge, 1993.

RAMOS, F. C. Horkheimer leitor de Schopenhauer: uma tradução e um breve comentário. Cadernos de Filosofia Alemã, São Paulo, USP, n.12, 2008.

RODRIGUEZ, J. R. Franz Neumann: o direito liberal além de si mesmo. In: NOBRE, M. (Org). Curso livre de teoria crítica. Campinas: Papirus, 2008.

SASSON, D. One hundred years of socialism. New York: The New Press, 1996.

ROSEMBERG, A. Democracia e socialismo. Global: 1999

TAYLOR, C. A política do reconhecimento. In: Argumentos filosóficos. São Paulo: Loyola, 2000. 


\section{CRITICAL THEORY AND THE SENSES OF EMANCIPATION}

\author{
Rúrion Melo
}

The tradition of thought known as Critical Theory, which has the names of Horkheimer, Adorno, Marcuse and Habermas, among many others, is comprised of various critical models. We find, in the same generation or even in the same author, different formulations of social criticism supported by renovated time diagnostics. This paper seeks to consider the conditions for renovation of the diagnoses from which the obstacles to emancipation and emancipatory potential, when present in a given society, are considered and analyzed critically. This renovation involves untying the normative foundation of the critique of the "productivist paradigm" and to conceive the emancipatory struggles in the plurality of their senses.

KeYwords: critical theory, emancipation, new social movements, democracy.

\section{LA THÉORIE CRITIQUE ET LES SENS DE L'ÉMANCIPATION}

\author{
Rúrion Melo
}

Composée de divers modèles critiques, la tradition de pensée connue comme Théorie Critique compte, entre autres, avec des noms tels que ceux de Horkheimer, Adorno, Marcuse et Habermas. Nous trouvons dans une même génération ou encore chez un même auteur, différentes manières de formuler la critique sociale basées sur des diagnostics renouvelés du temps. Cet article se veut de penser les conditions de renouvellement des diagnostics à partir duquel les obstacles à l'émancipation ou aux potentiels émancipatoires, lorsqu'ils existent dans une société donnée, doivent être considérés et analysés de manière critique. Ce renouvellement demande que le fondement normatif et la critique du "paradigme productiviste" soient séparés et suppose la conception de luttes émancipatoires dans la pluralité de leurs sens.

Mots-cLés: Théorie critique, émancipation, nouveaux mouvements sociaux, démocratie.

Rúrion Melo - Doutor em Filosofia. Professor de Teoria Política do Departamento de Ciências Sociais da Universidade Federal de São Paulo (UNIFESP). Coordenador do Grupo de Estudos de Política e Teoria Crítica da UNIFESP. Pesquisador do CEBRAP, desenvolvendo pesquisas na área de Filosofia Política e Teoria Crítica. Publicou recentemente $O$ uso público da razão: pluralismo e democracia em Jürgen Habermas (Loyola, 2011), e coorganizou Tensões e passagens: filosofia crítica e modernidade (2008) e Democracia deliberativa (2007), ambos publicados pela Singular/Esfera Pública. 